\title{
Ciudad, cultura y turismo: calidad y autenticidad
}

Carlos Romero Moragas

Departamento de Formación Instituto Andaluz del Patrimonio Histórico

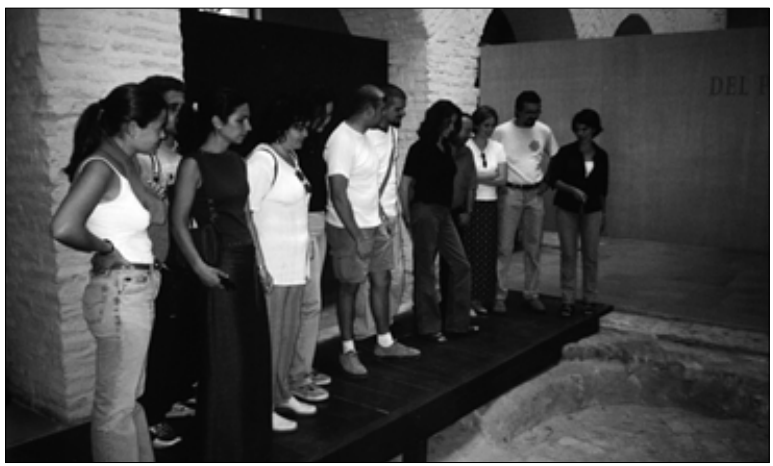

\section{Resumen}

El turista de motivación cultural, aunque minoritario, es el que nos interesa atraer a nuestras ciudades históricas, por su mayor capacidad de gasto y su menor impacto ambiental. Como contrapartida, este visitante es un experimentado viajero que exige calidad.

La calidad de la experiencia del turista de motivación cultural descansa sobre dos pilares: la accesibilidad y la autenticidad. Lo primero va referido a que el patrimonio esté suficientemente informado y señalizado para ser localizable; que su correcta conservación nos permita acceder y disfrutar de los monumentos y que los lugares de interés estén abiertos, con un horario amplio y públicamente anunciado. También está relacionado con todos aquellos servicios de interpretación que nos permiten disfrutar comprendiendo lo que visitamos.

El turista al que nos referimos es cada día más un experto conocedor de lugares de cultura y aprecia que detrás del patrimonio haya una actitud resuelta hacia su conservación y dinamización. Al turista cultural del futuro le gustará sentir que los lugares que visita son dinámicos culturalmente hablando y la autenticidad estribará en sentir que la ciudad esta viva y vibrante de contemporaneidad.

Cada vez somos más los turistas que no disfrutamos en ciudades donde la miseria se oculta y se ofrece al turista un falso espectáculo; donde la conservación ha sido más el resultado de la poca capacidad económica de la población para transformar la realidad que de una conciencia patrimonial o, por el contrario, un escenario museificado preparado para el turismo que ofrece la cultura como simulacro.

Por ello, las ciudades que pretendan competir con garantía y a largo plazo en el mercado del turismo cultural deberán poner a punto políticas públicas tendentes a lograr una ciudad socialmente más justa y cohesionada y una vida cultural propia, original, creativa, diversa y vibrante. El turista vendrá por añadidura, atraído por su autenticidad y vitalidad.

\section{Palabras clave}

Turismo cultural / Patrimonio cultural / Ciudades históricas / Autenticidad / Accesibilidad / Políticas públicas / Políticas culturales

\section{El turista cultural y la calidad}

Podemos considerar turista cultural aquella persona cuyo principal motivo para visitar una ciudad es conocer su patrimonio histórico (trama urbana, murallas, calles, plazas, palacios, iglesias, museos, etc.); observar y participar de las costumbres, idiosincrasias y modos de vida de la población residente (mezclarse en la calle, parques, restaurantes,.. con las población, comprar en sus tiendas, beber en sus bares, ...); asistir a manifestaciones de cultura tradicional (partici- 
La autenticidad es también resultado de la vitalidad del

patrimonio. Las ciudades deben estar vivas, habitadas, no

convertidas en museos. El turista huye cada día más de los

entornos esterilizados, estáticos y museificados en que se están

convirtiendo muchos centros históricos

par de la fiestas, gastronomía y folklore en general); presenciar representaciones culturales contemporáneas (conciertos, exposiciones de arte y otros espectáculos).

El turismo cultural es una actividad de ocio cada vez más generalizada que ofrece, como valor añadido sobre otro tipo de turismo, experiencias relacionadas con el saber y el aprendizaje. Esta forma de turismo activo se ha incrementado en los últimos tiempos y está influyendo en el descenso del tradicional mes de veraneo en la playa y a favor de períodos más cortos de vacaciones, distribuidos durante todo el año (Navidad, Semana Santa, etc.), en diversos destinos, nacionales e internacionales. A él hay que añadir el turismo de "puentes" fin de semana y el excursionismo, con un componente muy elevado de turismo cultural.

Dentro de la categoría de turista cultural podemos clasificar a los visitantes de las ciudades en tres tipos o segmentos, según sus diferentes actitudes o comportamientos:

- Turista de inspiración cultural, que elige destinos famosos por su patrimonio cultural (Toledo, Venecia, ...) para visitarlo una vez en la vida y con pocas intenciones de repetir. Suele viajar en grupos organizados con visitas en ruta a varias ciudades, sin una estancia prolongada en ninguna de ellas. Es el segmento de visitantes más abundante en las ciudades históricas y lo más parecido a turismo de masas por su forma de comercialización, comportamiento y consumo.

- Turista atraído por la cultura. Pasa sus vacaciones en un destino no cultural, como la playa o la montaña, pero no le importa, de forma ocasional, visitar lugares históricos y aprovechar las oportunidades culturales disponibles (ciudades, fiestas locales, museos, sitios arqueológicos, etc.). Es una forma de turismo creciente y en España tiene un ejemplo claro en los veraneantes extranjeros de la Costa de Sol que un día visitan la Alhambra.
- Turista de motivación cultural. Elige los lugares que visita en función de la oferta cultural que ofrecen. Está altamente motivado por aprender y prepara su viaje con antelación, informándose de lo que quiere ver. Pasa varios días en la ciudad o región elegida y realiza desplazamientos de corta duración por el entorno inmediato. (Jansen-Verbeke, M. 1997).

El turista de motivación cultural, nacional o extranjero, suele ser residente en una metrópolis o gran ciudad, de mediana edad, de considerable nivel educativo, medio o alto nivel adquisitivo y que viaja con asiduidad. En los países occidentales cada vez son más las personas adultas con tiempo libre, buena salud, que disfrutan viajando y perciben la visita a ciudades culturales como una experiencia de ocio por la que están dispuestos a pagar.

Este último tipo de visitantes, solo, con amigos o en familia, es al que nos vamos a referir en este artículo. Aunque representan una minoría del mercado turístico, nos parece el perfil más interesante para nuestras ciudades. Toda "ciudad inteligente" con pretensiones de promocionarse en el mercado del turismo cultural debe intentar atraer, retener el mayor tiempo posible y satisfacer las expectativas de este tipo de turistas con calidad, para que piense en volver $y$ se lo cuente a familiares y amigos.

Un municipio que quiera desarrollar una política seria y coherente en el terreno de turismo cultura nunca deberá facilitar o promover que se desarrolle en su ciudad una actividad relacionada con el turismo de masas: excursiones programadas con autobuses repletos de personas de dudoso interés en la cultura. Estos visitantes invaden la vía pública, alteran la vida normal de la ciudad y sus ciudadanos, contribuyen a degradar el paisaje urbano y los beneficios que aportan se lo reparten algunos operadores turísticos, guías, tiendas de recuerdos concertadas y pocos más.

Las ciudades responsables con importante patrimonio cultural deberían plantear cómo librarse de éste 

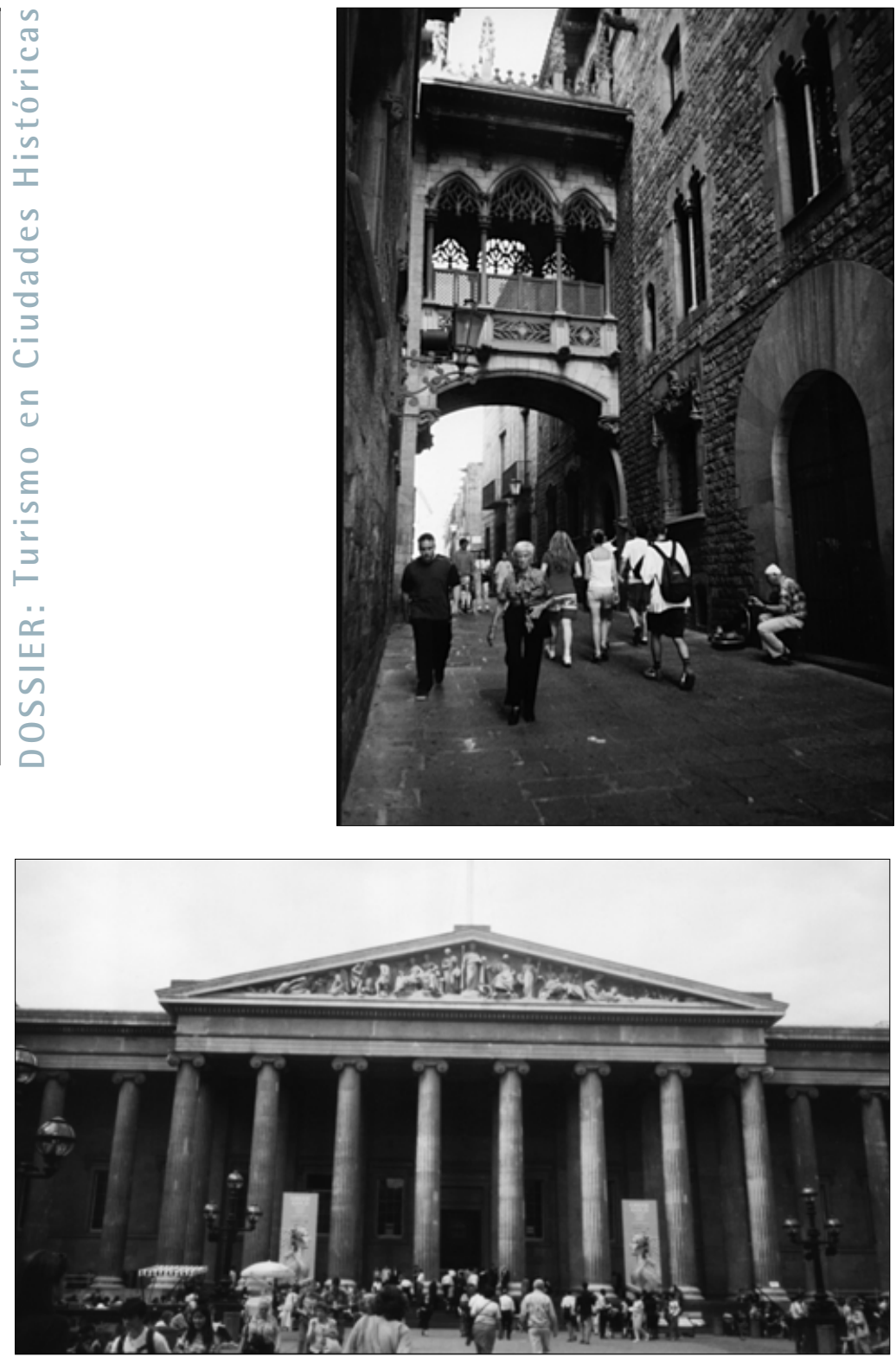

turismo de masas, de escaso valor añadido, que ocasiona más inconvenientes que ganancias y que sólo beneficia a una minoría en detrimento de la comunidad. Para esta modalidad de turismo están diseñados los parques temáticos y otros destinos similares que utilizan códigos culturales simplificados para ofrecerlos como simulacros y que suelen dar mejores resultados en la satisfacción del turismo de masas que el patrimonio cultural real.

El turista de motivación cultural, el que nos interesa atraer a nuestra localidad, suele ser un experimentado viajero que está dispuesto a pagar más por disfrutar de aquello que le gusta, pero que, como contrapartida, demanda calidad. Y ¿qué entendemos por calidad aplicada al turismo cultural?

Cuando el sector turístico habla de calidad casi siempre la asocia al servicio que prestan las agencias de viaje, hoteles o restaurantes. En este terreno se ha avanzado mucho y cada vez son mas las empresas que adoptan normas de calidad internacional- mente homologadas. Sin querer restar importancia a todo aquello que tiene que ver con la calidad del equipamiento y los servicios turísticos, consideramos que en turismo cultural esto no es suficiente. Al igual que el veraneante en la costa, además de unos servicios hoteleros de calidad, exige que la playa esté limpia y no contaminada y que haga sol-de no ser así su experiencia es incompleta o poco satisfactoria- el turista de motivación cultural que hemos definido anteriormente, demanda otras exigencias. Entendemos que la calidad de la experiencia del turista de motivación cultural descansa principalmente sobre dos pilares: la accesibilidad y la autenticidad, que a continuación pasamos a desarrollar como ejes fundamentales de nuestro discurso.

\section{Accesibilidad}

Utilizaremos el concepto de accesibilidad desde una consideración más amplia que en su uso habitual. Diferenciamos entre la accesibilidad física y la accesibilidad intelectual. La primera va referida a que el patrimonio y los recursos culturales estén suficientemente publicitados en guías, planos o folletos; señalizados para ser fácilmente localizables; abiertos al visitante con un horario amplio, públicamente anunciado; y que su correcta conservación nos permita acceder y disfrutar sin riesgo físico.

Cuántas veces hemos visitado ciudades en las que no hemos podido ver monumentos porque no estaban anunciados ni señalizados. Cuando los hemos por fin localizado están cerrados o con un horario de apertura muy restringido. Otras veces su estado de conservación es lamentable, no apto a la visita pública, con peligro de nuestra integridad física y de la del edificio. Por tanto, la primera norma de calidad en turismo cultural debería ir referida a que el patrimonio para su uso tiene que estar conservado, señalizado y abierto.

En segundo lugar, para entender a qué nos referimos con accesibilidad intelectual debemos plantearnos una pregunta previa: ¿Qué busca o qué placer piensa obtener una persona cuando ha elegido libremente y en su tiempo de ocio visitar una ciudad por su atractivo patrimonial o cultural?

En el caso concreto del patrimonio histórico, la satisfacción primaria que la mayoría de los turistas esperan obtener de su visita a un lugar patrimonial es el disfrute que genera la comprensión de lo que ven o experimentan y el valor positivo que le dan al hecho de aprender algo. Sentir que sabemos más, que somos un poco más sabios porque conocemos más cosas y las podemos ver en directo. (Prentice, R. 1993)

Para facilitar lo que hemos denominado accesibilidad intelectual, se utilizan herramientas de comunicación específicamente destinadas a los visitantes, como es, por ejemplo, la denominada interpretación del patri- 
monio. Este término, procedente de Norteamérica, lo introdujeron en Europa los ingleses para describir el proceso de comunicación que tiene lugar entre el público visitante y un lugar patrimonial específico. (Morales Miranda, J. 1998)

La interpretación se define como la habilidad de explicar el significado y trascendencia de un lugar patrimonial a la gente que lo visita. Su función es comunicar, hacer compresible el significado de los lugares patrimoniales a visitantes y turistas. La interpretación del patrimonio nació hace unos cuarenta y cinco años en el contexto de los parques naturales norteamericanos y en la última década es ampliamente utilizada en Europa asociada al patrimonio cultural. En países como Francia, Italia o España, la interpretación se ha impuesto a la museología tradicional en todo lo referente a la comunicación del patrimonio con sus usuarios, por su visión más adaptadas a las realidades del consumo cultural actual. (Romero Moragas, C. 1998)

Lo que diferencia la interpretación de otras formas de comunicación y educación se puede resumir en:

- va dirigida a un público en momentos de ocio y recreación, no como un acto académico que exija un duro esfuerzo;

- el objetivo es ayudar al público a que disfrute comprendiendo lo que visita, directamente sobre el lugar;

- la interpretación siempre asocia a su discurso un mensaje sobre la importancia que tiene la conservación del patrimonio y ayuda comprender el proceso necesario para llegar a ella. (Padró Werner, J. 1996)

Es indudable que en turismo cultural se ha avanzado bastante en el terreno relativo a la accesibilidad del patrimonio, aunque en muchos lugares o destinos culturales es todavía una asignatura pendiente.

\section{Autenticidad}

Pero quizá lo que cada día es más complejo ofertar es autenticidad. Es aquí donde radica el reto de las ciudades que quieran en el futuro competir en el mercado del turismo cultural urbano.

La autenticidad es un tema habitual en los foros profesionales del patrimonio cultural. Este concepto tradicionalmente se ha referido al alto grado de conservación de los objetos materiales que han pervivido del pasado: obras de arte, edificios singulares, conjuntos urbano o paisajes no transformados por la industrialización. También ha sido y todavía es muy valorado, y motivo de atracción turística, aquello relacionado con los usos y costumbre de los habitantes: modos de vida, fiestas, artesanías y cultura en general. Que todos estos elementos se conser- ven lo más inalterado posible siempre ha sido de gran valor para la industria turística!

En los últimos tiempos un nuevo concepto de autenticidad está naciendo, no exclusivamente unido al patrimonio construido, a su materialidad o a la conservación de modos de vida y costumbres ancestrales, sino a la capacidad que cada comunidad debe tener de escoger libremente vivir en el presente sin renunciar a su propia cultura, conservando su patrimonio y adaptando sus valores a nuevas necesidades y situaciones, de acuerdo a los Derechos Humanos. Estos últimos son universales y tienen prioridad sobre las tradiciones políticas, sociales y culturales. Ninguna cultura puede justificarse hoy día en contra los principios de democracia, libertad de expresión e igualdad de oportunidades.

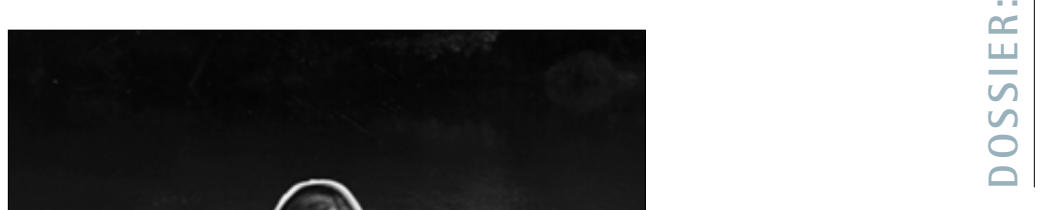

Frente a esto, una supuesta autenticidad se ofrece habitualmente al turismo, criticable en sus dos principales manifestaciones; bien por estar basada en la pobreza y la desigualdad; o bien por estar basada en el simulacro.

\section{Supuesta autenticidad basada en la pobreza y la de- sigualdad}

La autenticidad basada en la pobreza es propia de países o zonas territoriales subdesarrolladas que ofrecen al turista un lugar supuestamente "detenido en el tiempo" que conserva inalterado sus construcciones y sus costumbres, para ser disfrutadas por el visitante. Si entendemos por ciudades las aglomeraciones con cierto número de habitantes y medios 
de comunicación básicos (carreteras, televisión, teléfonos, ...), quedan pocas o ninguna "fuera del tiempo". Tras esa supuesta autenticidad suele esconderse atraso e injusticia social que condena a vivir a la mayoría de los ciudadanos en condiciones inaceptable para cualquier habitante de un país desarrollado.

Uno de los efectos añadidos de la globalización o mundialización es lo que podemos denominar "la pérdida de la inocencia". En otros tiempos el turista cultural, normalmente un norteamericano o centro europeo residente en una gran ciudad, era una persona privilegiada que podía visitar el patrimonio que habían creado las diversas culturas, desaparecidas o no, a lo largo el mundo y asombrarse de la grandeza, belleza y originalidad de los distintos lugares. La miseria la achacaba a regímenes políticos injustos y tiranos, costumbres arcaicas y atrasadas o ni siquiera se lo planteaba sus motivos.

En la actualidad somos cada vez más conscientes de que como habitantes de denominado primer mundo estamos en buena parte en el origen de numerosas catástrofes y miserias humanas en todo el planeta; que nuestras posibilidades económicas de viajar están vedadas a la inmensa mayoría de los seres humanos; que con nuestra presencia contribuimos a la destrucción de la originalidad cultural que por un lado vemos y admiramos; que lo que es atractivo y exótico para nosotros puede ser no más que atraso y miseria para sus poseedores.

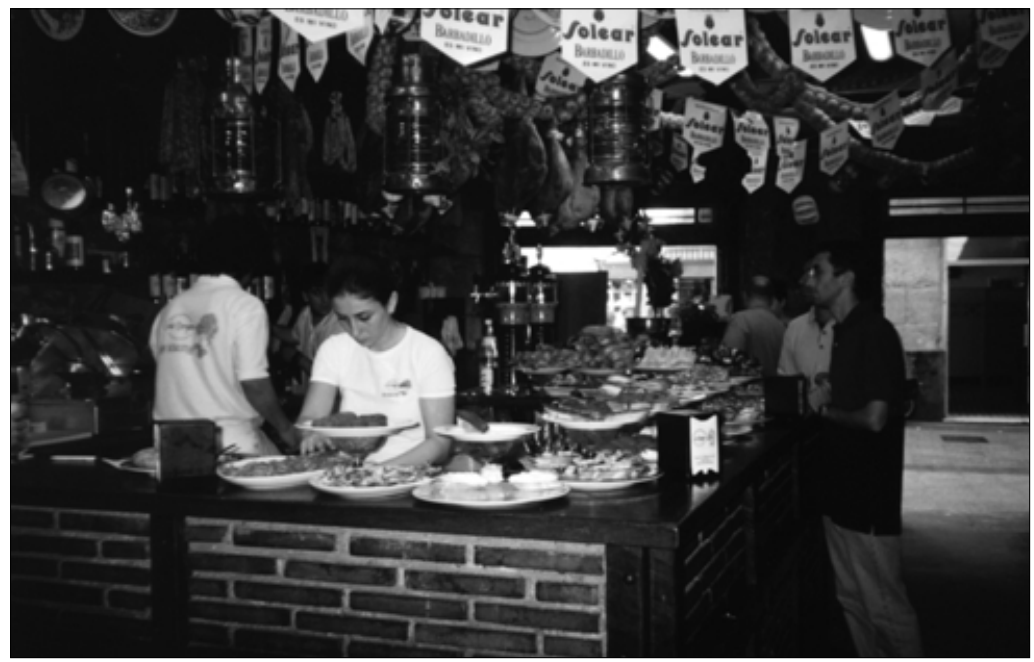

Esta pérdida de la inocencia es tanto por parte de los visitantes como de los visitados. Países con graves problemas económicos y sociales ven en el turismo internacional una manera de equilibrar su balanza de pago. Aunque esto siempre ha sido así con el denominado turismo de sol y playa, el impacto social sobre las poblaciones residentes es mucho menor al estar concentrado en lugares costeros, de nueva planta, expresamente creados para la actividad turística.

Pero el turismo cultural se desarrolla en la ciudad, en sus calles y espacios públicos, donde viven, trabajan y se divierten los residentes. El impacto social es mu- cho mayor cuando se observa el alto poder económico de los turistas. Para que la actividad turística se desarrolle sin incidentes se intenta acotar y presentar la parte más simbólica y monumental de la ciudad. Una frontera invisible marca claramente lo que es para los turistas y lo que es para los locales. El visitante que se salte estas delimitaciones insinuadas por las agencias de viaje, hoteles, planos turísticos, o el sentido común, se expone a toda clase de peligros o situaciones desagradables. El que no se arriesga a salir de esos espacios acotados, si es inteligente, sabe que lo que ve y vive del lugar que visita es una representación preparada expresamente para él. Fuera de allí todo es distinto y puede ser peligroso.

En casi todas partes del mundo ya saben lo qué es un turista, su capacidad adquisitiva, las ventajas económicas inmediatas que significa tratarlos. El viajero cada vez se siente más intranquilo y acosado. Por una parte sabe que lo que visita no es exactamente real, que con su dinero a lo mejor fomenta la tiranía y que si sale de lo organizado para el turista se expone a peligros. El residente ve en el turista una forma de obtener beneficios fáciles e impensables de otro modo.

El viajero contemporáneo es cada vez más sensible a que la autenticidad de la que disfruta, por su condición privilegiada de habitante del mundo desarrollado que paga en dólares, sea a costa del atraso y la injusticia social. Contra esto se argumenta que si no fuera por el turismo la vida en estas ciudades sería mucho peor. Pero ello no quita al turista inteligente cierta sensación de culpabilidad que le impide disfrutar plenamente de su visita. Cada vez somos más los turistas que no disfrutamos en ciudades donde la miseria se oculta y se ofrece al turista un falso espectáculo; donde la conservación es producto de la poca capacidad económica de la población para transformar sus condiciones de vida: un producto del atraso económico y la injusticia social.

\section{Supuesta autenticidad basada en el simulacro}

En los países desarrollados hay cierto consenso sobre el interés de la conservación física del patrimonio y es una necesidad plenamente asumida por nuestros gobernantes, técnicos urbanistas y por los ciudadanos. El debate se centra más en el cuánto y en el cómo.

En cuatro podemos agrupar los principales peligros que amenazan la autenticidad de la ciudad histórica y que por tanto repercuten en la calidad del turismo cultural: degradación, terciarización, gentrificación y banalización.

Entendemos por degradación el abandono físico de sectores o barrios de la ciudad por envejecimiento de la población, deterioro de la edificación, infravivienda, deficiente infraestructura urbana, ausencia de servicios y marginalidad. Esto puede llegar a desembocar en la destrucción física de los edificio, del espacio urbano y la degradación social. 
Terciarización es el proceso por el cual los centros urbanos que fueron residenciales o multifuncionales en otro tiempo, por su centralidad, acaban destinados para uso exclusivo del sector servicios: comercios, restaurantes, edificios públicos y oficinas. El hábitat pierde importancia y fuera del horario comercial estos lugares céntricos de las ciudades quedan desiertos.

La gentrificación o aburguesamiento es la sustitución de la población residente tradicional, de composición social diversa, por otra con un perfil más uniforme y alto poder adquisitivo. A partir de la rehabilitación hay un proceso de transformación y sustitución del tejido social dentro del centro histórico. El coste económico de los edificios rehabilitados es por lo general más elevado que los de nueva planta, por lo que los precios de venta o de alquiler aumentan cada vez más a medida que la rehabilitación progresa y da una fisonomía más atractiva al centro. La población tradicional residente, sobre todo las familias de bajos ingresos, son progresivamente empujadas hacia las periferias en beneficio de aquellos capaces de asumir alquileres y precios más altos, con el consiguiente empobrecimiento de la diversidad social que siempre ha caracterizado los centros urbanos de nuestras ciudades.

La banalización es sobre todo resultado del turismo, al concentrar y especializar sectores de la ciudad en esta actividad. Es una forma de terciarización de gran impacto paisajístico, que favorece nuevas arquitecturas historicistas, falsos decorados, tiendas de recuerdos de baja calidad, restaurantes con publicidad agresiva, masificación turística, etc. Pero sobre todo influye en que eleva los precios de la vivienda en el sector y expulsa actividades comerciales normales y equipamientos básicos para los residentes: tiendas de comestibles, colegios, etc.

Degradación, terciarización, gentrificación y banalización, juntos o por separado, juegan en contra de la autenticidad. Estos cuatro fenómenos son consecuencia del abandono de la ciudad a su suerte o a intereses privados. En la última década han primado visiones productivistas o simplemente especulativas que han afectado muy negativamente a la autenticidad de la ciudad.

En algunas ciudades las actuaciones públicas para la recuperación de los centros históricos se han centrado en sus aspectos puramente físicos y ha consistido en la mejora de las infraestructura de saneamiento, restauración de monumentos, peatonalización y puesta en valor para la visita turística de ciertas zonas con un aspecto histórico patrimonial. La rehabilitación del caserío, salvo ayudas puntuales, se ha dejado completamente a la iniciativa privada y al mercado inmobiliario, con ausencia de programas de vivienda social, lo que ha dado como resultado centros históricos llenos de estudios, apartamentos de alquiler o casas unifamiliares de elevados precios. Es difícil encontrar una vivienda normal de tres dormitorios a un precio razonable para una familia media.

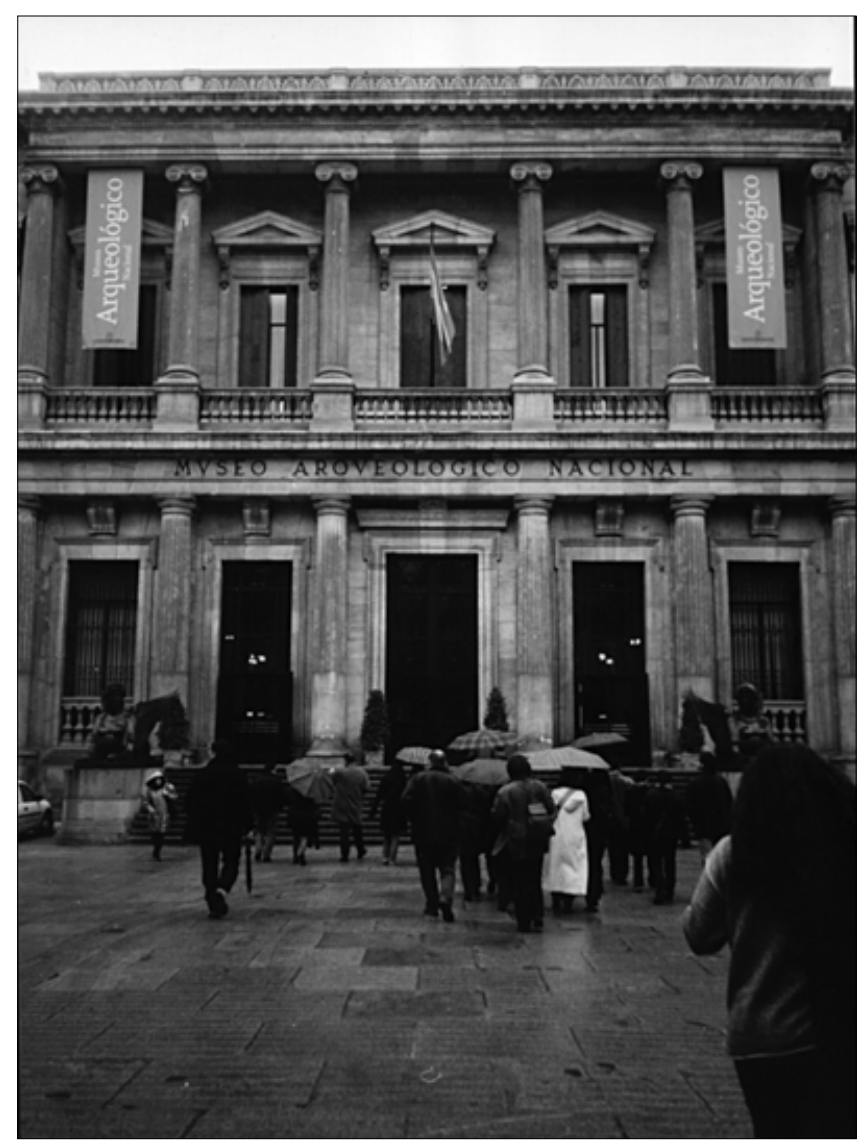

Esto trae como consecuencia centros históricos vacíos o escasamente habitados por una población en alquiler y de paso.

A este fenómeno también han contribuido algunas políticas públicas conocidas como de "marketing urbano", de inspiración mercantilista neoliberal. En la década de los ochenta y sobre todo en los noventa, los municipios europeos se ven obligados a ofrecer respuesta a sus ciudadanos de las consecuencias negativas que sobre sus ciudades trae la globalización (deslocalización de capitales, desindustrialización, paro y crisis fiscal) promoviendo estrategias de desarrollo local. Se abordan iniciativas de dinamización económica a partir de recursos propios. Las ciudades compiten entre ellas para atraer y fijar el capital cada vez más mudable, llevando a cabo políticas activas de creación de empleo y desarrollo local.

Las ciudades compiten por llamar la atención en el terreno nacional e internacional. Hay que hacerse notar, "poner la ciudad en el mapa". La puesta en valor y promoción turística de la cultura y del patrimonio cultural será una de las áreas fundamentales de actividad. Se trata de remodelar el paisaje urbano para transformar la imagen de la ciudad de cara al exterior y hacia la población residente. Para ello se eligen sectores simbólicos de la ciudad y se lleva a cabo su transformación mediante nueva arquitectura o rehabilitaciones de calidad y cuidado diseño. También se fomenta en su entorno una atmósfera lúdica y de ocio, con restaurantes y bares, salas culturales o centros comerciales. 


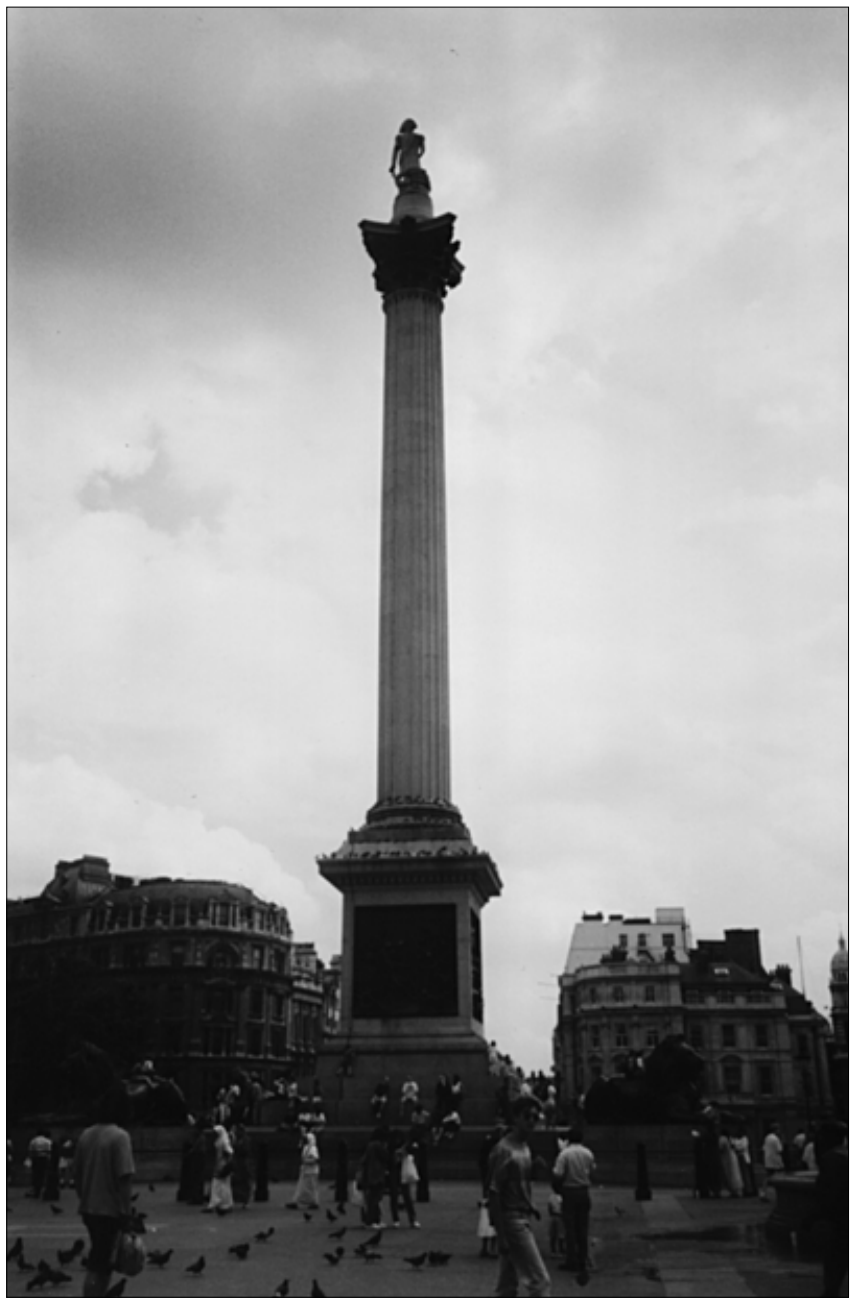

Las ventajas que para las ciudades han tenido estas intervenciones de "marketing urbano" han sido, por ejemplo, mayores inversiones en la recuperación física de los cascos históricos degradados; la creación de nuevos equipamientos de ocio y cultura; el diseño de entornos agradables y de calidad; o el fortalecimiento del orgullo local y aprecio de los ciudadanos hacia su ciudad.

Por el contrario, los inconvenientes de fomentar una ciudad demasiado volcada al visitante y a su imagen exterior, han venido derivados de focalizar las inversiones en puntos simbólicos (frentes de agua, plazas mayores, grandes equipamientos culturales, etc.) o en megaeventos. El "marketing urbano" desvía la atención sobre problemas estructurales que existen en la ciudad y concentra las inversiones en los centros urbanos y actuaciones emblemáticas, en detrimento de las periferias donde viven la mayoría de los ciudadanos. El esfuerzo presupuestario realizado en estas actuaciones y en la organización de grandes eventos -a favor de la exaltación del espectáculo y de lo efímero- van normalmente en detrimento de las políticas sociales y de cohesión.

Los nuevos espacios recuperados para la ciudad suelen ser demasiado parecidos unos a otros, "desprovistos de alma", museificados. Se peca de repetición y homogeneización, con entornos cultos, lim- pios, seguros, de ocio,.. rodeados de barrios infradotados o deprimidos. También ha supuesto la subida general de los precios de las vivienda y la gentrificación de los barrios en los centros urbanos. (González Cevallos, S. 2000)

\section{Políticas públicas y modelo de ciudad}

Los turistas de motivación cultural vienen a las ciudades históricas por su patrimonio y su cultura. Pero la industria turística no invierte en la protección, conservación y puesta en valor del patrimonio cultural. Ellos sólo se ocupan de la infraestructura turística (hoteles, restaurantes, agencias, etc.), a lo más en marketing promocional. ¿Quién se encarga entonces de sensibilizar a la población en la protección del paisaje urbano y la conservación del patrimonio edificado,? ¿Quién se ocupa de educar a los habitantes para que conozcan su patrimonio cultural y puedan compartirlo con los visitantes? La complejidad de la conservación de una ciudad histórica no se puede basar únicamente en una labor "restauradora de la piedra". Los ciudadanos tienen que querer su ciudad y para ello deben conocer su historia y valorar sus peculiaridades, su estilo de vida.

Una ciudad es siempre una realidad más compleja que un espacio para el turismo. Una ciudad es una comunidad de intereses, con tensiones y contradicciones entre sus ciudadanos. Por ello se diferencia de un parque temático, exclusivamente diseñado para la satisfacción de sus visitantes/clientes. El turista de motivación cultural viene a ver ciudades originales que han conservado su personalidad y de algún modo participar de su contemporaneidad, no a parques temáticos o escenificaciones que ofrezcan la cultura como simulacro.

La autenticidad es también resultado de la vitalidad del patrimonio. Las ciudades deben estar vivas, habitadas, no convertidas en museos. El turista huye cada día más de los entornos esterilizados, estáticos y museificados en que se están convirtiendo muchos centros históricos. Hay que reforzar la autenticidad de las ciudades, sobre todo mediante la consolidación del hábitat y la reinserción de las funciones propias de las zonas urbanas. Sólo teniendo en cuenta a los usuarios locales se puede conseguir eso. Los turistas vendrán después, atraídos por la vitalidad y la veracidad del lugar. La restauración de los edificios y del paisaje debe estar subordinada al objetivo primordial de rehabilitar la vida urbana. (Viau S. 1992)

¿Es compatible la rehabilitación de inmuebles con la rehabilitación de la vida social y cultural?, o por el contrario ¿un barrio rehabilitado es un barrio museificado? ¿Es posible este tipo de rehabilitación de los edificios y de la vida social dejándolo únicamente en manos del libre mercado inmobiliario? o ¿es necesaria la intervención de la Administración para garantizar la permanencia de los vecinos y evitar su esterilización y museificación? 
La autenticidad de las ciudades debe sustentarse sobre dos premisas:

- un modelo social de ciudad;

- una vida cultural propia, actual, diversa y vibrante.

Para ambas son necesarias políticas públicas comprometidas con el futuro de la ciudad que favorezcan una sociedad mas igualitaria; políticas públicas que luchen contra la pobreza y la exclusión social; políticas urbanas que refuercen la conservación del patrimonio y la cohesión social; y políticas culturales activas contra la banalización y el simulacro.

La intervención desde los ayuntamientos es fundamental para definir modelos económicos, sociales y territoriales para las ciudades, lo que implica dotar sus actuaciones de fuerte componente político e ideológico. Los proyectos políticos y la acción social son esenciales para mejorar la sociedad.

El sector público debería jugar un papel preeminente, plenamente comprometido en la transformación de las condiciones que generan necesidad y desprotección. Los municipios tienen capacidad para actuar en la transformación social y favorecer la redistribución de la riqueza y la solidaridad, contribuyendo a la construcción social de un espacio urbano que evite la segregación. La mejor inversión que puede hacer un municipio en turismo cultural es fomentar una ciudad socialmente cohesionada, interviniendo, mediante políticas públicas, contra la pobreza y exclusión social, reduciendo las desigualdades en todos los terrenos e impulsando mejoras en la calidad de vida, el bienestar del conjunto de la población y la convivencia ciudadana. (Brugué, Q. y Goma, R. 1998)

Los poderes locales también pueden ejercer un fuerte impacto en el urbanismo y la creación de espacio público, condición indispensable para garantizar la cohesión social, configurando una realidad urbana donde lo colectivo gane terreno frente a la privacidad. Dejar exclusivamente al mercado la rehabilitación del casco histórico conduce sólo a viviendas de lujo o apartamentos y estudios de alquiler para población de paso, pero no se podrá consolidar un hábitat normal, para familias de diverso poder adquisitivo. Los mecanismos reguladores están en manos de la Administración, a través de reglamentaciones y mecanismos financieros que ayuden a la construcción de vivienda social. El reto es conseguir que los cascos históricos sean espacios generadores de cultura a partir de los nuevos ingredientes humanos. Si no es así estarán condenados a ser un mero escenario para el comercio, el turismo y las representaciones de la cultura tradicional ofrecidas como espectáculo.

Junto a una política social es necesario llevar a cabo actuaciones urbanas:

- reequilibrar mediante inversiones equitativas los distintos sectores de la ciudad;
- regenerar los tejidos urbanos multidegradados;

- construir con calidad el espacio público, tanto en su urbanismo como en cualquier tipo de equipamientos y servicios complementarios;

- recuperar espacios emblemáticos, simbólicos e identitarios, sobre todo de los centros históricos, primando el uso público y la sociabilidad;

- consolidar el hábitat en las zonas históricas y su carácter urbano multifuncional

- contrarrestar los procesos de terciarización, desertización o gentrificación de los cascos históricos. (Troitiño Vinuesa, M.A. 1999)

El modelo promocional, comunitario y estratégico de bienestar local requiere una gestión que supere la segmentación y el centralismo tecnoburocrático y los sustituya por un modelo de producción de servicios integrado, descentralizado, participativo y pluralista. Los Ayuntamientos han de asumir roles relacionales que faciliten la coordinación y el liderazgo estratégico de todas aquellas energías sociales y comunitarias que puedan ser puestas al servicio de la resolución de necesidades.

La posibilidad de que las instancias locales realicen aportaciones estratégicas al desarrollo y al bienestar de sus ciudades debe entenderse en el contexto del estilo relacional de gobierno. Un estilo que implica gobernar a través de redes de actores interdependientes y no de jerarquías decisionales legalmente establecidas. Los gobiernos municipales deben pasar a desarrollar un papel dinamizador creando relaciones y redes horizontales de participación de distintas administraciones (público), organizaciones ciudadanas (asociativo), empresas (privado), creando esquemas de integración descentralizados, participativos, pluralistas, integrales, estratégicos mediante plataformas, partenariados, consorcios, convenios, etc., Es decir, se trataría de:

- transferir poder a la comunidad;

- suavizar el peso de la burocracia;

- tender a estructuras flexibles de gestión pluralista. (Brugué, Q. y Goma, R. 1998)

\section{Turismo y política cultural}

El turista de motivación cultural cada día es más experto conocedor de lugares de cultura y aprecia una serie de cosas, entre ellas, que detrás del patrimonio cultural haya una actitud resuelta hacia su conservación y dinamización. Demanda ciudades actuales y reales, con una vida cultural propia, donde al turista se le pueda ofrecer la autenticidad producto de un desarrollo peculiar y no escenarios "demasiado petrificados" y "limpios", o "demasiado auténticos", pro- 


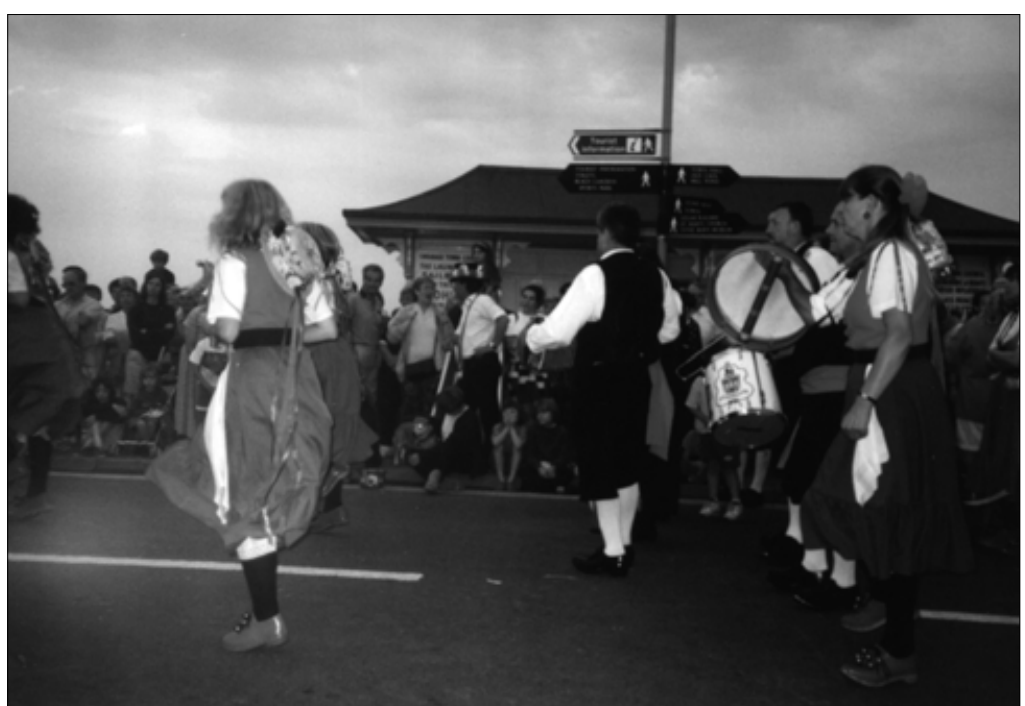

ducto de un atraso económico secular. Al visitante le gusta sentir que la ciudad es dinámica culturalmente hablando y no un cascarón vacío. Le gusta que los artesanos y artistas recrean nuevas formas a partir de la tradición, que haya equipamientos culturales que funcionen y una vida cultural intensa y diversa. La autenticidad estriba en sentir que la ciudad esta viva y vibrante de contemporaneidad.

El patrimonio cultural y el modo de vida local singulariza una ciudad o región, contrarrestando el fenómeno homogeneizador de la cultura globalizada a través de los medios de comunicación de masas. Pero si el pasado y la tradición no es capaz de innovarse, queda anquilosada. Desde la singularidad de lo local debemos ser capaces de operar en un entorno global: hay que integrar tradición (pasado, patrimonio material e inmaterial) con modernidad e innovación. Local/global, tradición/innovación; espacio y tiempo. El cruce de estos vectores marca el ámbito conceptual sobre el que construir estrategias de desarrollo 2 .

La mejor inversión que una ciudad puede hacer en turismo cultural es reforzar su autenticidad, propiciando un modo vida urbana propio, original y diversa. Los turistas vendrán después, atraídos por su veracidad y vitalidad.

La ciudad y la vida urbana es el principal espacio creador de cultura. La cultura a su vez es un elemento estratégico para la ciudad, un recurso fundamental para el desarrollo local. El sector cultural tiene potencialidad para genera empleo directo y es fundamental para sectores cercanos como el turismo. Atrae la inversión al generar valor añadido al entorno donde se desarrolla y dinamiza la innovación de cualquier sector económico. Tiene capacidad para integrar y cohesionar a los ciudadanos, facilitando el acceso al conocimiento y mejorarando la igualdad de oportunidades.

Todo municipio tiene que afianzar y desarrollar su identidad y poseer un proyecto de futuro donde la cultura sea parte fundamental. Para ello, independien- temente de su tamaño y localización, debe contar con unos equipamientos y servicios básicos mínimos y adoptar una política cultural propia enmarcada en una política municipal que tenga en cuenta sus particularidades históricas y territoriales, los agentes existentes, las propuestas asociativas y privada. También debe contar con recursos económicos y humanos y establecer estrategias culturales globales vinculadas a sus programas de planificación y desarrollo. Un sector cultural fuerte, operativo, adaptado al contexto, abierto a la creación y a los avances tecnológicos, capaz de llegar al conjunto de los ciudadanos ${ }^{3}$.

Por tanto:

- Todo municipio, independientemente de su tamaño, localización o riqueza, debe poseer los medios suficientes para poder plantear y ejecutar una política cultural, sólo o en cooperación con otras entidades, acorde con sus necesidades, sus posibilidades y sus aspiraciones.

- Cada ciudad necesita una política cultural única, no dispersa, enmarcada en una política municipal que tenga en cuenta la realidad territorial, los agentes existentes, las propuestas asociativas y privadas, el desarrollo progresivo de las iniciativas y propuestas para captar nuevos públicos, nuevos creadores, nuevas producciones.

Las políticas culturales deben ser plurales, participativas, integradoras y enriquecedoras. Tradicionalmente han sido cuatro las orientaciones claves que han guiado la intervención pública en cultural:

- reforzar la identidad de los ciudadanos con su comunidad, con su pasado y con su patrimonio;

- posibilitar la diversidad de las manifestaciones culturales (culta, popular, étnicas, etc.);

- fomentar la creatividad y la producción de nuevas obras que serán el patrimonio del futuro;

- animar a la participación y posibilitar el acceso de todos los ciudadanos a la vida cultural de la forma más activa posible. (VV.aa, 1999)

La misión de la administración es facilitar que surja la "vida cultural", democratizarla, no ser competidor de otras iniciativas públicas o privadas y corregir los defectos de forma subsidiaria, sin olvidar en ningún momento que los verdaderos protagonistas de la cultura son los ciudadanos como creadores, organizadores de eventos, conservadores y transmisores de su pasado, productores y comercializadores.

Toda ciudad debe contar con un área de cultura que aúne investigación y conocimiento, conservación, puesta en valor, dinamización y fomento de la creación, así como una política de turismo cultural basada en la puesta en valor de esos recursos. Los sectores posibles de actuación pública municipal en cultura son: 
- preservación del patrimonio cultural; planificar la acción sobre el patrimonio local;

- fomento de la creación; garantizar el desarrollo de las formas de creación menos comerciales;

- posibilitar el acceso a las nuevas tecnologías o nuevas formas de creación, producción y consumo cultural;

- promoción de las producciones culturales locales, industriales o artesanales, facilitando su comercialización.;

- cultura y turismo; hacer accesible físicamente y comprensible la cultura a los visitantes;

- cultura y comunicación; presencia activa de las producciones y actuaciones locales en los medios de comunicación;

- cultura y educación; acercar la cultura a la escuela y colaborar estrechamente con la red educativa;

- fomento de la fiesta y la cultural en vivo; facilitar la función social de la cultura;

- apoyo al asociacionismo y voluntariado cultural. (López Aguileta, I. 2000)
En conclusión, el turismos cultural se deben explotar las diferencias culturales, no las similitudes. Por tanto, hay que reforzar esas diferencias, ponerlas en valor y difundirlas, de forma que haya interacción entre el turista y la cultura local. Los retos de las ciudades que quieran promocionar turísticamente su cultura son:

- que el turismo sirva a las necesidades de la ciudad y de los ciudadanos y no al contrario;

- que las estrategias turísticas enriquezcan el patrimonio y la cultura de la ciudad en lugar de simplificarla, banalizarla o destruirla.

Las localidades con un importante patrimonio cultural que quieran promocionarse turísticamente deben supeditar el turismo a una política cultural que asegure la autenticidad y sostenibilidad del sistema. El turista debe percibir que detrás de los lugares de su interés hay un modelo social de ciudad, una política local, en la cual el patrimonio y la cultura cumplen una misión fundamental como elementos simbólicos, identitarios de la comunidad y no un escenario adaptado al negocio turístico. El reto es transformar la calidad de vida de la población local en garantía de autenticidad y que revierta en la calidad de la experiencia turística del visitante.

\section{Bibliografía}

BRUGUÉ, Q. y GOMA, R. (1998) Gobiernos locales y políticas públicas. Bienestar social, promoción económica y territorio. Barcelona: Ariel, 1998

GONZÁLEZ CEVALLOS, S. (2000) El ocio en la ciudad emprendedora. EN $6^{\circ}$ Congreso Mundial de Ocio, área temática: espacio y cultura [cd-rom]. Deusto: Universidad, 2000.

JANSEN-VERBEKE, M. (1997) Urban tourism. Managing resources and visitors. EN Salah Wahab y John J. Pigram (eds). Tourism, development and growth: the challenge of sustaninability. Londres; Nueva York: Routledge, 1997, pp.237-256.

LÓPEZ AGUILETA, I. (2000) Cultura y ciudad. Manual de política cultural municipal. Gijón: Trea, 2000

MORALES MIRANDA, J. (1998) Guía Práctica para la Interpretación del Patrimonio. Sevilla: Consejería de Cultura de la Junta de Andalucía, 1998

PADRÓ WERNER, J. (1996) La interpretación: un método para promover el usos social del Patrimonio Cultural y Natural. Difu- sión del Patrimonio Histórico, Sevilla: Consejería de Cultura, Instituto Andaluz del Patrimonio Histórico, 1996, pp. 8-13

PRENTICE, R. (1993) Tourism and Heritage Atractions, London: Routledge, 1993

ROMERO MORAGAS,C. (1998) La ciudad histórica y las estrategias de comunicación. En Vivir las Ciudades Históricas. Universidad de Extremadura y Fundación La Caixa, 1998

TROITIÑO VINUESA, M.A. (1999) Turismo y recuperación funcional de los centros históricos. En Vivir las Ciudades Históricas, Fundación la Caixa, pp. I I5-127

V.AA. (1999) Sueños e identidades. Una aportación al debate sobre cultura y desarrollo en Europa. Barcelona: ITERART/Península, 1999 (Edición en castellano de In From the Margins. Consejo de Europa 1996)

VIAU, S.(1992) La Tétralogie de Québec: Capitale, Patrimoine, Culture et Turisme. En Le Patrimonine atout du developpement. Lyon: Centre J. Cartier; Presses Universitaires de Lyon, pp. I I5- 126.
I. Sobre el concepto de autenticidad puede consultarse la conferencia internacional que con este fin se celebrado en Nara, Japón, del I al 5 de noviembre de 1994, organizada por ICOMOS, ICCROM y el Centro de Patrimonio Mundial de la UNESCO, de donde surge la Declaración de NARA. Una traducción al castellano está en el Boletín PH del Instituto Andaluz del Patrimonio Histórico n I I de junio de 1995.
2. Extraído del Plan Estratégico del Sector Cultural de Barcelona elaborado por el Institut de Cultura de Barcelona. El Plan puede ser consultado en www.bcn.es/icub/accentcultura.

3. Argumentos contenidos en el documento denominado Mapa Cultural de Sabadell, finalizado en 1995, dirigido por Pere Vidal para el Ayuntamiento de Sabadell. 